\title{
No influence of supplemental dietary calcium intake on the bioavailability of spinach carotenoids in humans
}

\author{
Joana Corte-Real ${ }^{1,2,3}$, Cédric Guignard ${ }^{2}$, Manon Gantenbein ${ }^{1}$, Bernard Weber ${ }^{4}$, Kim Burgard $^{4}$, \\ Lucien Hoffmann ${ }^{2}$, Elke Richling ${ }^{3}$ and Torsten Bohn ${ }^{1 *}$ \\ ${ }^{1}$ Population Health Department, Luxembourg Institute of Health, 1A-B, rue Thomas Edison, L-1445 Strassen, Luxembourg \\ ${ }^{2}$ Environmental Research and Innovation Department, Luxembourg Institute of Science and Technology, 41, rue du Brill, \\ L-4422 Belvaux, Luxembourg \\ ${ }^{3}$ Food Chemistry and Toxicology, Department of Chemistry, University of Kaiserslautern, Erwin-Schroedinger-Strasse 52, \\ D-67663 Kaiserslautern, Germany \\ ${ }^{4}$ Laboratoires Réunis Luxembourg S.A., 38, rue Hiehl, L-6131 Junglinster, Luxembourg
}

(Submitted 17 February 2017 - Final revision received 24 May 2017 - Accepted 25 May 2017-First published online 27 June 2017)

\begin{abstract}
Dietary carotenoid intake, especially from fruits and vegetables, has been associated with a reduced incidence of several chronic diseases. However, its bioavailability can vary, depending on the food matrix and host factors. Recently, it has been suggested that divalent minerals negatively impinge on carotenoid bioavailability by reducing bile-salt and non-esterified fatty-acid levels in the gut, which normally aid in emulsifying carotenoids. The aim of the present study was to investigate whether supplemental Ca would negatively influence carotenoid absorption in humans. A total of twenty-five healthy, non-obese men (age: $20-46$ years, BMI $<30 \mathrm{~kg} / \mathrm{m}^{2}$ ) were recruited for this postprandial, randomised, crossover, double-blinded trial. Following a randomised block design, each participant received (after 2-week washout periods), on three occasions separated by 1 week, $270 \mathrm{~g}$ of spinach-based meals (8.61 (sD 1.08) mg carotenoids/100 g fresh weight), supplemented with 0,500 or $1000 \mathrm{mg}$ of $\mathrm{Ca}$ (as calcium carbonate), with each participant acting as his or her own control. Blood samples were collected at regular postprandial intervals for up to $10 \mathrm{~h}$ following test meal intake, and standardised lunches were served. TAG-rich lipoprotein fractions were separated and carotenoid concentrations determined. AUC for meals without supplemented Ca were $22 \cdot 72$ (SEM 2.78) nmol $\times \mathrm{h} / \mathrm{l}$ (lutein), $0.19($ (sem 3.90) $\mathrm{nmol} \times \mathrm{h} / \mathrm{l}(\beta$-carotene) and 2.80 (sEm 1.75) nmol $\times \mathrm{h} / \mathrm{l}$ ( $\beta$-cryptoxanthin). No significant influence of supplementation with either 500 or $1000 \mathrm{mg}$ of supplemental Ca was found. In conclusion, $\mathrm{Ca}-$ the most abundant divalent mineral in the diet - given at high but physiological concentrations, does not appear to have repercussions on the bioavailability of carotenoids from a spinach-based meal.
\end{abstract}

Key words: Calcium: Carotenoids: Bile-salt complexation: Soap formation: Digestion

Carotenoids are natural pigments that can be produced by plants, bacteria and certain fungi, but not by humans. Their dietary intake, especially in the form of fruits and vegetables, as well as circulating tissue levels have been associated in epidemiological studies with not only the reduced incidence of several chronic diseases including cardiometabolic complications $^{(1,2)}$ and some types of cancer ${ }^{(3,4)}$, but also with all-cause mortality ${ }^{(5)}$, though their contribution to vitamin A intake, especially in developing countries and for vegetarians, is also important ${ }^{(6,7)}$. Furthermore, low carotenoid intake has been associated with age-related macular degeneration ${ }^{(8,9)}$, the major cause of blindness in the elderly.

The exact mechanism by which carotenoids act on the host is unknown, though direct antioxidant properties ${ }^{(10)}$ and anti-inflammatory as well as antiapoptotic effects produced by acting on gene transcription ${ }^{(11)}$ may play a role. However, the bioavailability of carotenoids is extremely variable, depending on carotenoid type, dietary (i.e. matrix-related) factors ${ }^{(12,13)}$ and host factors ${ }^{(14,15)}$. For instance, a diet rich in lipids and low in dietary fibre has been proposed to increase the bioavailability of carotenoids $^{(16,17)}$, mainly by improving bioaccessibility - that is, the fraction of carotenoids that are available for cellular uptake in the small intestine ${ }^{(18)}$ - as both conditions increase the fraction of emulsifiable carotenoids, a prerequisite for their absorption.

Recently, it has been suggested that dietary divalent minerals may negatively impinge on carotenoid bioavailability, as they could bind to bile salts and NEFA in the gut, resulting in

Abbreviations: CIEC, Clinical Investigation and Epidemiological Center; TRL, TAG-rich lipoprotein.

* Corresponding author: T. Bohn, fax +352 26532 872, email Torsten.bohn@gmx.ch 
their precipitation and unavailability for emulsification. This emulsification is crucial in order to allow for mixed-micelle formation and assure solubilisation of the lipophilic carotenoids. However, so far, this negative effect has only been demonstrated in vitro, following simulated gastrointestinal digestion $^{(19)}$, and also following carotenoid cellular uptake into Caco-2 cells, a frequently employed model of the small intestinal lining ${ }^{(20)}$. In addition, concentrations required to reduce carotenoid bioaccessibility and cellular uptake have been shown to be quite high, possibly not reachable by trace elements, not even in supplement form. However, a high but physiological intake of $\mathrm{Ca}$ and $\mathrm{Mg}$, such as those obtained via supplements, at concentrations reflecting approximately 33 and $100 \%$ of the RDA ( $1000 \mathrm{mg}$ for $\mathrm{Ca}$ and $400 \mathrm{mg}$ for $\mathrm{Mg}$ for adult males), respectively ${ }^{(21)}$, have been shown to reduce micellarisation and cellular uptake by over $60 \%{ }^{(20)}$. The observed reductions in carotenoid bioaccessibility were further well associated with increased surface tension and reduced viscosity in vitro, also suggesting precipitation of emulsifying compounds as the likely mechanism ${ }^{(19)}$. However, as the in vitro methods that have been employed thus far represent rather static models - that is, not accounting for potential dynamic adaptations of the human body with respect to enzyme and bile-salt secretions - such findings are rather suggestive and do not constitute definite proof.

In the present human study, we aimed to prove or disprove the hypothesis that dietary divalent minerals, and specifically $\mathrm{Ca}$, are able to hamper the emulsification and thus the bioavailability of carotenoids from a vegetable matrix. For this purpose, Ca was given in the form of supplements together with a spinach meal, and the TAG-rich lipoprotein (TRL) fraction, representing newly absorbed carotenoids, was measured postprandially over time.

\section{Methods}

\section{Chemicals}

Unless otherwise stated, all chemicals used were of analytical or superior quality and were procured from Sigma-Aldrich. Carotenoid standards were from Sigma-Aldrich ( $\beta$-carotene, lycopene, internal standard trans- $\beta$-apo- 8 -carotenal) and Carotenature (lutein, $\beta$-cryptoxanthin, violaxanthin, neoxanthin, phytofluene). Only $18 \mathrm{M} \Omega$ (Millipore) water was used.

$\mathrm{Ca}$ capsules and the placebo were produced by a private company, Econophar SPRL and contained either $250 \mathrm{mg}$ of elemental Ca (as carbonate) or $560 \mathrm{mg}$ of mannitol, respectively. Formulation of $\mathrm{Ca}$ capsules followed that of a commercially available Ca supplement, Steocar $250 \mathrm{mg}$ gelatine capsules from Nycomed.

\section{Participants}

A total of twenty-five male participants were recruited for this study. For this purpose, flyers were distributed at various places in Luxembourg and an advertisement was also issued via email and word-of-mouth. Inclusion criteria were: being male, being between 18 and 50 years of age, living independently in Luxembourg, being healthy and not being obese $\left(\mathrm{BMI}<30 \mathrm{~kg} / \mathrm{m}^{2}\right)$. Exclusion criteria were having any chronic diseases, use of antibiotics during the past 6 months, regularly taking supplements, being vegetarian/vegan, being obese $\left(\mathrm{BMI}>30 \mathrm{~kg} / \mathrm{m}^{2}\right)$, consuming more than 2 units of alcohol $/ \mathrm{d}$ regularly, engaging in regular physical exercise for $>150 \mathrm{~min} / \mathrm{d}$, having a haematocrit value $<35 \%$ or a $\mathrm{Hb}$ level $<12 \mathrm{~g} / 100 \mathrm{ml}$, having fasting blood glucose concentrations $>120 \mathrm{mg} / \mathrm{dl}$, being hyperlipidaemic (having both total cholesterol and TAG concentrations $>200 \mathrm{mg} / \mathrm{dl}$ ), having any food allergies, being a current smoker or having a recent smoking history (past 2 years) or typically consuming $>$ five portions of fruits/vegetables per day. Subjects with any history of malabsorption or surgery in the digestive tract were also excluded. The study was approved by the National Research Ethics Committee (CNER, www.cner.lu) of Luxembourg (Protocol 201305/05), and was conducted according to the Declaration of Helsinki. The study was carried out at the Clinical Investigation and Epidemiological Center (CIEC) of the Luxembourg Institute of Health.

\section{Study design}

For recruitment, all subjects were informed in detail about the study design as well as its risks and benefits, and those willing to participate signed a written informed consent form. At a first eligibility screening (Fig. 1), subjects were asked to fill out a 'Health and Lifestyle' questionnaire, and their height, weight, body fat (percentage by impedance method, Touch II balance; Ozeri) and waist and hip circumferences were measured. Subjects were considered eligible if they did not meet any of the exclusion criteria, and were scheduled for a second screening. A fasting blood sample was collected for haematology and lipid-profile analysis (TAG, total cholesterol, LDL-cholesterol and HDL-cholesterol). Subjects also donated a urine spot-sample to screen for any physiological abnormalities and to assure eligibility to participate in the trial. For this purpose, GAK Combi Screen Plus 9 strips were obtained from Analytikon, allowing for testing of glucose, ketones, ascorbic acid, pH, leucocytes, nitrite, proteins, blood and bilirubin in a urine spot-sample. Subjects considered eligible at this stage were enrolled for the trial phase, and will be referred to as participants henceforth.

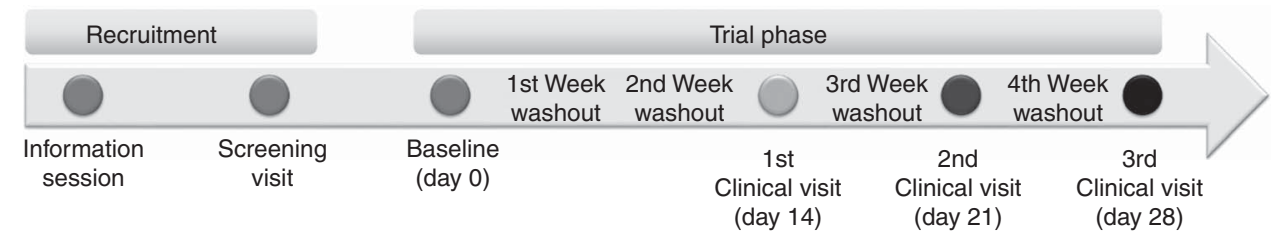

Fig. 1. Design of the clinical trial. 
The trial phase had a total duration of 4 weeks, which included an initial 2 weeks of washout (i.e. participants were asked to restrict themselves from consuming carotenoidcontaining foods as much as possible) and three clinical visits that were 1 week apart, during which participants were asked to continue the washout diet. A randomised block design with all six possible combinations of $\mathrm{Ca}$ intake sequences was employed (high, medium-low $v$. medium-high-low, etc., with four participants per block). Randomisation was achieved by lots, carried out by the statistical group of the Department. Both participants and all personnel included in carrying out the trial were blinded. The study, from recruitment to finalisation, was carried out between July 2012 and July 2015.

At the start of the trial phase, participants visited the CIEC premises to give a $12 \mathrm{~h}$ fasting blood sample for assessment of glucose, blood lipids, $\mathrm{Ca}$ and plasma carotenoid levels at the beginning of the washout phase. During the following 2 weeks, participants were asked to follow a diet low in carotenoids. For this purpose, participants received a list with foods to avoid and a list with foods allowed. This included not only frequently consumed food items rich in carotenoids, such as green leafy vegetables, bell peppers, tropical fruits and some local fruits such as plums and apricots as well as tomato and tomato products but also certain animal products such as egg yolk and salmon. The list of allowed foods was to ensure suggesting alternatives, including onions, apples, pears and other food items typically low in carotenoids (<approximately $0.5 \mathrm{mg}$ / $100 \mathrm{~g}$ ). In addition, participants received a booklet and were asked to enter major meals on a daily basis. Following the washout phase, participants arrived for their first clinical visit. After an overnight fast $(12 \mathrm{~h})$, participants reported to the general clinical research facility between 06.30 and 07.00 hours. Upon arrival, the participant's weight and body fat (\%) were measured and a catheter was placed into the arm of the participant by a trained nurse. A first blood sample $(20 \mathrm{ml})$ was obtained and investigated for plasma carotenoids, TRL carotenoids, blood lipids, blood glucose and Ca. For this purpose, separate Vacuette $^{\circledR}$ (Greiner Bio-One $\mathrm{GmbH}$ ) type tubes were employed. For carotenoid analyses, $10 \mathrm{ml}$ Vacuette K-EDTA tubes were used.

Participants were then given the test meal, which had to be consumed within $30 \mathrm{~min}$. Following this, successive blood samples $(20 \mathrm{ml})$ were collected postprandially at 2, 3, 4, 5, 6, 8 and $10 \mathrm{~h}$. At noon, a standardised lunch was served. Following the $10 \mathrm{~h}$ clinical stay, a complimentary snack was offered that is, the participants were free to choose from various sandwiches. During the entire clinical visit, no own foods or beverages were allowed. Participants stayed under medical supervision on the premises of the CIEC postprandially, for $10 \mathrm{~h}$.

Following this clinical visit, each participant maintained an additional washout time of 1 week, before visiting the CIEC premises for the second full clinical day, and a similar procedure was followed for a third visit. In total, each participant had three full stays at the CIEC premises, receiving either the meal with 500 or $1000 \mathrm{mg}$ of elemental $\mathrm{Ca}$, or the Ca-free placebo. Thus, the intervention differed only in the amount of Ca supplemented. Doses were chosen so as to reflect approximately the half and full recommended dietary allowance (RDA) of $\mathrm{Ca}$, being 500 and $1000 \mathrm{mg}$ (for healthy males/females aged 19-50 years), respectively. All other meals and beverages served during the clinical days were identical.

\section{Test meals}

Each participant received for breakfast one glass of water $(300 \mathrm{ml}$ ) low in minerals (total mineral content $<40.0 \mathrm{mg} / \mathrm{l}$, with a Ca content of $1.0(\mathrm{SD} 0.3) \mathrm{mg} / \mathrm{l}), 270 \mathrm{~g}$ of microwave-heated spinach to which $18 \mathrm{ml}$ of rapeseed oil was added in order to foster carotenoid bioavailability, and $40 \mathrm{~g}$ toasted (white wheat) bread served with $20 \mathrm{~g}$ cream cheese (17.5\% fat). Spinach was chosen despite its content of dietary fibre and oxalic acid, as it is a frequently consumed vegetable rich in carotenoids ${ }^{(22)}$, and as it was the focus of several earlier in vitro trials ${ }^{(20,23,24)}$ with which we wished to compare our results. Nutrient composition was estimated from information given on the labels, and, if not available, by employing a local database as well ${ }^{(22)}$. Each test meal contained approximately $1255 \mathrm{~kJ}$ (300 kcal) energy, $18 \mathrm{~g}$ fat, $21 \mathrm{~g}$ carbohydrates, $13 \mathrm{~g}$ proteins, $8 \mathrm{~g}$ dietary fibre and $390 \mathrm{mg} \mathrm{Ca}$. Together with the meal, four capsules containing the placebo, 500 or $1000 \mathrm{mg}$ of elemental Ca were given, which were swallowed with the water, after the spinach portion had been consumed. Thus, the three test meals differed only in their total Ca content, which was approximately $390 \mathrm{mg}$ for the placebo meal, $890 \mathrm{mg}$ for the $500 \mathrm{mg}$ Ca dose and $1390 \mathrm{mg}$ for the $1000 \mathrm{mg}$ Ca dose. Ca was given in the form of carbonate, which is among the most used $\mathrm{Ca}$ supplements. The total carotenoid content in the morning test meal was approximately $23 \mathrm{mg}$ (Table 1). Considering the content of provitamin A carotenoids, it can be estimated that this portion delivered approximately $10 \%$ of the daily vitamin A requirements (RDA) ${ }^{(25)}$.

For lunch, each participant received $300 \mathrm{ml}$ of water with low mineral content, one banana, one toasted sandwich (white wheat bread, approximately $60 \mathrm{~g}$ ) with approximately $60 \mathrm{~g}$ turkey and butter (10 g) and one portion of Greek yogurt $(2.5 \%$ fat level, $140 \mathrm{~g}$ ), containing a total of $2188 \mathrm{~kJ}$ ( $523 \mathrm{kcal}$ ) energy, $22 \mathrm{~g}$ protein, $24 \mathrm{~g}$ fat, $52 \mathrm{~g}$ carbohydrates and $4 \mathrm{~g}$ of fibre. The Ca content was approximately $207 \mathrm{mg}$. Water with low mineral content (Ca content approximately $1 \mathrm{mg} / \mathrm{l}$ ) was allowed between meals upon request.

Food items were purchased at local supermarkets (CORA SA or CACTUS SA). Spinach was purchased in frozen form from the same batch and stored in the freezer at $-20^{\circ} \mathrm{C}$ until the day before serving. Aliquots of spinach were kept for later analysis of carotenoid content.

Table 1. Average content of the individual carotenoids in the spinach meal

(Mean values and standard deviations; $n$ 23)

\begin{tabular}{lccc}
\hline & \multicolumn{3}{c}{ Content per $100 \mathrm{~g}(\mathrm{mg} / 100 \mathrm{~g})$} \\
\cline { 2 - 3 } Carotenoids & Mean & SD & Content in test meal $(\mathrm{mg})$ \\
\hline Lutein & 5.59 & 0.69 & 15.10 \\
$\beta$-Carotene & 0.38 & 0.34 & 1.02 \\
Neoxanthin & 0.72 & 0.11 & 1.94 \\
Violaxanthin & 1.87 & 0.40 & 5.05 \\
Sum & 8.61 & 1.08 & 23.25 \\
\hline
\end{tabular}




\section{Sample processing}

Samples were collected according to the study design (see above), and were either processed in-house (carotenoids) or by an external commercial laboratory (accredited according to ISO 15189) for glucose, Ca, lipids and haematology (Laboratoires Réunis). This external laboratory was accredited in 2006 and undergoes periodic surveillance by an accreditation committee from Luxembourg. Different kinds of Vacuette ${ }^{\circledR}$ tubes were employed depending on the type of analysis to be performed: Vacuette K-EDTA tubes were used for carotenoid and haematology analysis; Vacuette Na-Fluoride tubes were used for glucose analysis; and Vacuette Serum Gel tubes were used for the analysis of lipids. The latter were centrifuged on site, according to laboratory guidelines. In short, the tubes were left standing (upright position) for $30 \mathrm{~min}$ to allow clotting. The tubes were then centrifuged for $10 \mathrm{~min}$ at $1670 \mathrm{~g}$, at $20^{\circ} \mathrm{C}$, and maintained at room temperature until pickup. Quantitative determination of TAG was carried out using the Roche/Hitachi Cobas C analyser following the manufacturer's instructions (Roche Diagnostics).

All blood samples collected for later carotenoid determination were left standing for $5 \mathrm{~min}$ and spun down for $6 \mathrm{~min}$ at $20^{\circ} \mathrm{C}$ in a Sigma $2-16 \mathrm{KC}$ centrifuge ( ${ }^{(}$Thermo Fisher Scientific Inc.) at $2060 \mathrm{~g}$. Following separation of the blood plasma, the TRL fraction rich in chylomicrons was separated similarly as described earlier ${ }^{(26,27)}$. In short, $2.9 \mathrm{ml}$ of plasma was overlayered with $1.4 \mathrm{ml}$ of a $1.006 \mathrm{~g} / 1 \mathrm{NaCl}$ solution in a $4 \mathrm{ml}$ propylene conical ${ }^{\mathrm{TM}}$ Quick-Seal ${ }^{\circledR}$ (Beckman Coulter) tube, and TRL fractions were separated at $170000 \boldsymbol{g}$ for $1 \mathrm{~h}$ at $4{ }^{\circ} \mathrm{C}$ in a Beckman Optima ${ }^{\mathrm{TM}}$ C-90U Ultracentrifuge (Beckman Coulter) with a SW 40-Ti titanium swinging-bucket rotor. The lower plasma phase was removed by puncturing the vials, and the upper TRL fraction $(0.5 \mathrm{ml})$ was separated and brought up to $1.5 \mathrm{ml}$ using $0.9 \% \mathrm{NaCl}$, frozen in $\mathrm{N}_{2}$ and stored at $-80^{\circ} \mathrm{C}$. Likewise, plasma samples were stored at $-80^{\circ} \mathrm{C}$ for carotenoid analyses.

\section{Extraction of carotenoids}

Carotenoids were extracted from spinach samples as described earlier ${ }^{(24)}$. Blood plasma and plasma TRL fraction extraction protocols were adapted from Unlu et al. ${ }^{(27)}$. In short, after the addition of $3.25 \mathrm{ml}$ ethanol containing $0.1 \%$ butylated hydroxytoluene (BHT) to approximately $1.5 \mathrm{ml}$ of TRL fraction or to $1.0 \mathrm{ml}$ of plasma, fractions were left to stand on ice for $5 \mathrm{~min}$ and were spun down at $4^{\circ} \mathrm{C}$ for $2 \mathrm{~min}$, at $600 \mathrm{~g}$. The supernatant was collected into a new tube and the precipitates were re-extracted with $3 \mathrm{ml}$ of diethyl ether-hexane $(1: 2, \mathrm{v} / \mathrm{v})$ containing $0.02 \%$ BHT. Samples were centrifuged at $1250 \boldsymbol{g}$ for $2 \mathrm{~min}$ at $4^{\circ} \mathrm{C}$. Supernatants were combined, to which $2 \mathrm{ml}$ of saturated $\mathrm{NaCl}$ was added. Samples were extracted once with $4 \mathrm{ml}$ of hexane + BHT $(0.02 \%)$, and a second time with $3 \mathrm{ml}$ diethyl ether-hexane $(1: 2, \mathrm{v} / \mathrm{v})$. Extracts were spun down for $1 \mathrm{~min}$ at $1250 \mathrm{~g}$ to remove any water remnants, transferred into new tubes and evaporated to dryness under a stream of $\mathrm{N}$ in a TurboVap LV (Biotage) apparatus. Tubes were then flushed with $\mathrm{Ar}$, and samples were stored at $-80^{\circ} \mathrm{C}$ until analysis.

\section{Carotenoid analysis}

Before measurements, samples were reconstituted with methanol-methyl-tert-butyl-ether (7:3) in volumes of $600 \mu \mathrm{l}$ (plasma samples), $100 \mu \mathrm{l}$ (TRL fraction) or $6 \mathrm{ml}$ (spinach extracts). During this procedure, an aliquot of internal standard (trans- $\beta$-apo-8'-carotenal) was also added, to obtain a final concentration of $1 \mu \mathrm{g} / \mathrm{ml}$ (spinach and plasma extracts) or $0 \cdot 1 \mu \mathrm{g} / \mathrm{ml}$ (TRL extracts).

Carotenoid analyses were carried out using liquid chromatography as reported previously ${ }^{(24)}$. In brief, separation was achieved using an Agilent 1260 Infinity U-HPLC instrument, in combination with gradient elution. Eluents were: (A) water$\mathrm{MeOH}$ (60:40) containing $30 \mathrm{~mm}$ of ammonium acetate, and (B) acetonitrile-dichloromethane (85:15). Elution gradient was as follows: $0 \mathrm{~min}, 48 \% \mathrm{~B}$; $4 \mathrm{~min}, 48 \% \mathrm{~B} ; 5 \mathrm{~min}, 52 \% \mathrm{~B} ; 11 \mathrm{~min}$, $52 \% \mathrm{~B} ; 13 \mathrm{~min}, 75 \% \mathrm{~B} ; 18 \mathrm{~min}, 90 \% \mathrm{~B}$; $35 \mathrm{~min}, 90 \% \mathrm{~B} ; 36 \mathrm{~min}$, $42 \%$ B. An Accucore C30 column (2.6 $\mu \mathrm{m}$ particle size, $2 \cdot 1 \mathrm{~mm}$ i.D. $100 \mathrm{~mm}$ length; Thermo Fisher Scientific Inc.) at $28^{\circ} \mathrm{C}$ was used for separation of carotenoids. The injection volume was $10 \mu \mathrm{l}$. Carotenoids were detected using a coupled UV/vis photodiode array detector and identified according to their retention times and spectral data, based on comparison with the corresponding individual standard. All peaks were integrated manually at $350 \mathrm{~nm}$ (phytofluene), $440 \mathrm{~nm}$ (neoxanthin and violaxanthin), $450 \mathrm{~nm}$ (lutein and $\alpha$-carotene), $455 \mathrm{~nm}$ ( $\beta$-carotene, $\beta$-cryptoxanthin and internal standard) and at $470 \mathrm{~nm}$ (lycopene), according to each carotenoid's absorption maxima. Quantification was achieved using the internal standard method, with trans$\beta$-apo-8'-carotenal used as the internal standard.

\section{$A \cup C$ and $C_{\max }$}

The postprandial AUC of time $v$. concentration of the respective carotenoids extracted from TRL fractions was determined on the basis of seven postprandial time points plus the baseline (fasting state, before test meal intake). Concentrations of carotenoids were determined using the internal standard method. The AUC was then determined from baseline-corrected (each concentration was subtracted from its baseline value) values using the trapezoidal method. Individual $C_{\max }$ values reflect the highest carotenoid concentrations measured in the TRL fraction of one participant on one clinical day, irrespective of the time point, and these were used to calculate the average $C_{\max }$.

\section{Statistical analyses}

Unless otherwise stated, all data are reported as means and standard deviations. Normality and equality of variance of AUC data reflecting bioavailability were tested using normality plots and box plots, respectively.

For the sample size, it was estimated that, even following several drop-outs, twelve to fifteen participants would provide sufficient statistical strength to observe a difference in carotenoid absorption. For example, a difference in carotenoid absorption of approximately 5\% (e.g. $10 v$. 15\%) could be resolved in a pairwise design with a relative standard variation of fractional (\%) absorption of approximately $50 \%$ for an $\alpha$ of 
0.05 and a power of $80 \%$ (http://www.quantitativeskills.com/ sisa/calculations/samsize.htm). With twenty-three participants, an absorption of $3.5 \%$ (11 v. 14.5\%) could be detected with an $\alpha$ of 0.05 and a power of $80 \%$. For comparing the effect of $\mathrm{Ca}$ dosing, a generalised linear univariate model was employed for each carotenoid and TG, with baseline-corrected AUC as the observed dependent variable, and carotenoid (lutein, $\beta$-carotene, $\beta$-cryptoxanthin), participant, sequence of intervention (visits 1,2 or 3 ) and supplemental-Ca dose (0, 500 $1000 \mathrm{mg}$ ) as the independent, fixed factors. TRL baseline concentration (time $0 \mathrm{~h}$ on each test day, i.e. before test meal intake) of each respective carotenoid was also included as a covariate. Following significant Fisher's $F$ tests, all pairwise comparisons were carried out using Fisher's protected LSD (least significance difference) test. Values with $P<0.05$ (two-sided) were regarded as statistically significant.

\section{Results}

\section{Drop-out rate and arbitrary effects, description of} participants

A total of twenty-five healthy and free-living male participants, between 20 and 46 years of age, were enrolled in the study. The BMI of the participants ranged from 16.9 to 29.5 (average 24.8 $(\mathrm{sD} 2 \cdot 8) \mathrm{kg} / \mathrm{m}^{2}$ ), and the measured body fat (\%) was between $2 \cdot 0$ and $22 \cdot 1$ (average 13.3 (SD 4.9)\%). Total cholesterol and TAG concentrations ranged from 118 to 305 (average 179.7 (sD 44.8) $\mathrm{mg} / \mathrm{dl}$ ) and from 36 to 207 (average 81.0 (sD 41.4) $\mathrm{mg} / \mathrm{dl}$ ), respectively (Table 2 ). Despite some elevated cholesterol ( $n$ 6) and TAG values ( $n$ 1) observed, the participants were still admitted into the study under the advice of a medical doctor. No participant had both TAG and total cholesterol concentrations $>200 \mathrm{mg} / \mathrm{dl}$.

Serum carotenoid profile and concentrations were also investigated. The following carotenoids were identified in the fasting plasma samples of the participants: $\beta$-carotene $(0.45(\mathrm{SD} 0.37) \mu \mathrm{m})$;

Table 2. Anthropometric characteristics and fasting blood biochemistry from twenty-five male participants, at the time of recruitment (Mean values and standard deviations)

\begin{tabular}{|c|c|c|c|c|}
\hline & Mean & SD & Minimum & Maximum \\
\hline \multicolumn{5}{|l|}{ Anthropometric measures } \\
\hline Age (years) & 30 & 8 & 20 & 46 \\
\hline Height $(\mathrm{cm})$ & $176 \cdot 9$ & $5 \cdot 3$ & $167 \cdot 0$ & $185 \cdot 0$ \\
\hline Weight (kg) & 77.5 & $10 \cdot 0$ & $52 \cdot 3$ & 97.7 \\
\hline BMI $\left(\mathrm{kg} / \mathrm{m}^{2}\right)$ & $24 \cdot 8$ & $2 \cdot 8$ & $16 \cdot 9$ & 29.5 \\
\hline Body fat $(\%)^{*}$ & $13 \cdot 3$ & 4.9 & 2.0 & $22 \cdot 1$ \\
\hline Waist $(\mathrm{cm})$ & 85.9 & 8.4 & $66 \cdot 0$ & $102 \cdot 0$ \\
\hline Hip (cm) & 98.7 & 5.7 & $82 \cdot 0$ & $108 \cdot 0$ \\
\hline Waist/hip & 0.87 & 0.07 & 0.70 & 1.00 \\
\hline \multicolumn{5}{|l|}{ Blood biochemistry profile† } \\
\hline Glucose $(\mathrm{mg} / \mathrm{dl})$ & 85.4 & $12 \cdot 0$ & 53.0 & $109 \cdot 0$ \\
\hline Cholesterol (mg/dl) & $179 \cdot 7$ & 44.8 & $118 \cdot 0$ & $305 \cdot 0$ \\
\hline HDL-cholesterol (mg/dl) & $56 \cdot 5$ & 13.0 & $36 \cdot 0$ & $90 \cdot 0$ \\
\hline Non-HDL-cholesterol (mg/dl) & $122 \cdot 0$ & $40 \cdot 3$ & 71.0 & $215 \cdot 0$ \\
\hline LDL-cholesterol (mg/dl) & $104 \cdot 8$ & 39.4 & $57 \cdot 0$ & $203 \cdot 0$ \\
\hline TAG $(\mathrm{mg} / \mathrm{dl})$ & 81.0 & 41.4 & $36 \cdot 0$ & $207 \cdot 0$ \\
\hline $\mathrm{Ca}(\mathrm{mmol} / \mathrm{l})$ & $2 \cdot 3$ & $0 \cdot 1$ & $2 \cdot 1$ & 2.5 \\
\hline
\end{tabular}

${ }^{*}$ Measured using impedance method. † Fasting blood levels. lutein (0.13 (sD 0.08) $\mu \mathrm{m}) \alpha$-carotene together with 9-cis- $\beta$-carotene (0.07 (sD 0.07) $\mu \mathrm{m}) ; \beta$-cryptoxanthin (0.10 (sD 0.08) $\mu \mathrm{m})$; lycopene $(0.51(\mathrm{sD} 0.36) \mu \mathrm{m})$; and phytofluene $(0.18$ (sD 0.13) $\mu \mathrm{m})$ (Table 3$)$. $\mathrm{Ca}$ levels in plasma at the time of the first screening were $2 \cdot 35$ (sD 0.10) $\mathrm{mmol} / \mathrm{l}$ (i.e. $94.2(\mathrm{sD} 4.0) \mathrm{mg} / \mathrm{l}$ ), and within the reference levels provided, and thus did not vary widely.

Among the enrolled participants, one dropped out for personal reasons, after the first clinical visit. For one other participant, the number of pills packed during production were two instead of four, meaning that the participant was given a placebo dose once and a $500 \mathrm{mg}$ dose of $\mathrm{Ca}$ supplement twice. Finally, the results from the first participant enrolled in the study were excluded from further plasma TRL analysis, as samples from this participant were used for method-optimisation purposes. In summary, twenty-four participants completed the trial, and data were analysed for twenty-three of the twenty-five participants.

All participants consumed the totality of the three test meals that were given, plus the supplement pills, without any observed adverse effect. Nevertheless, some participants had more difficulty than others in finishing their spinach dose, requiring up to approximately $20 \mathrm{~min}$, which introduced some variability in the time-span of the test meal intake.

\section{Washout phase}

Participants were asked to avoid, as far as possible and during the entire trial phase, carotenoid-containing food items. After 2 weeks of initial washout, the concentration of total serum carotenoids decreased significantly $(P<0 \cdot 01)$, on average by approximately $38 \%$ (Fig. 2), with an approximately $30 \%$ decrease for both lutein and $\beta$-carotene (twenty-four participants). However, we did observe that for some participants, there was an increase in the plasma circulation of some of the individual carotenoids (data not shown).

\section{Influence of calcium supplements on the AUC of serum TAG and carotenoids in the plasma TAG-rich plasma lipoprotein fraction}

Contrary to what was expected, supplementation with either 500 or $1000 \mathrm{mg}$ of Ca did not significantly affect the absorption of carotenoids from a spinach-based meal (Fig. 3). Although the values for the AUC for test meals supplemented with $1000 \mathrm{mg}$ of elemental Ca were generally inferior to those of the other two groups, differences were not statistically different and variance

Table 3. Blood plasma carotenoid concentrations of the participants at the time of recruitment $(n 25)$

(Mean values and standard deviations)

\begin{tabular}{lcccc}
\hline & Mean & SD & Maximum & Minimum \\
\hline Lutein $(\mu \mathrm{M})$ & 0.13 & 0.08 & 0.34 & 0.03 \\
$\beta$-Carotene $(\mu \mathrm{M})$ & 0.45 & 0.37 & 1.46 & 0.00 \\
$a$-Carotene $(\mu \mathrm{M})^{\star}$ & 0.07 & 0.07 & 0.28 & 0.00 \\
$\beta$-Cryptoxanthin $(\mu \mathrm{M})$ & 0.10 & 0.08 & 0.27 & 0.00 \\
Lycopene $(\mu \mathrm{M})$ & 0.51 & 0.36 & 1.08 & 0.00 \\
Phytofluene $(\mu \mathrm{M})$ & 0.18 & 0.13 & 0.39 & 0.00 \\
Total carotenoids $(\mu \mathrm{m}) \dagger$ & 1.43 & 0.89 & 3.40 & 0.05 \\
\hline
\end{tabular}

* $\alpha$-Carotene represents concentration of both $\alpha$-carotene and 9 -cis- $\beta$-carotene. † Sum of all individual carotenoids listed above. 
was high (Table 4). A statistically significant influence was found for participant $(P<0 \cdot 01)$ and the sequence of visit $(P=0.012)$. For TAG, a biphasic curve pattern was found, with peaks at approximately 2 and $6 \mathrm{~h}$ postprandially (after lunch intake).

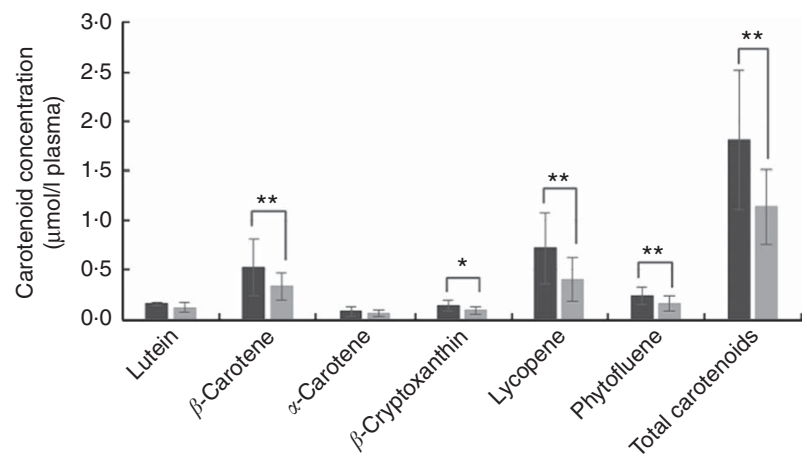

Fig. 2. Effect of 2 weeks of washout on blood plasma carotenoids. Fasting plasma carotenoid concentrations were assessed at day $0(\square)$ of the trial phase, and participants were asked to restrict themselves to a washout diet (i.e. avoiding, as far as possible, the consumption of carotenoid-containing foods) for a period of 2 weeks. Fasting plasma carotenoid concentrations were assessed once more on the day of their first clinical visit (day 14, $\square$ ), and values were compared to evaluate the effect of washout on the reduction of plasma carotenoid concentrations. Values are means ( $n$ 23) and standard deviations represented by vertical bars Total carotenoids include: lutein, $\beta$-cryptoxanthin, $\beta$-carotene, $\alpha$-carotene +9 -cis- $\beta$-carotene, lycopene and phytofluene. Statistical significant difference between the two measures of each carotenoid: ${ }^{*} P<0.05,{ }^{*} P<0.01$.

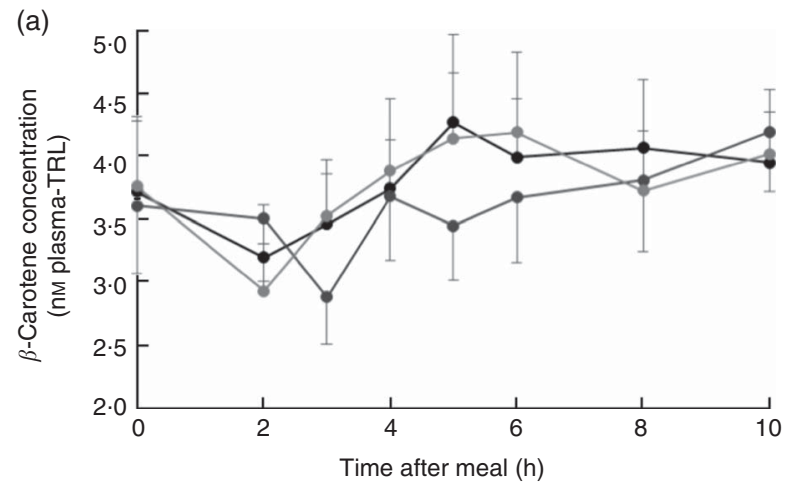

(c)

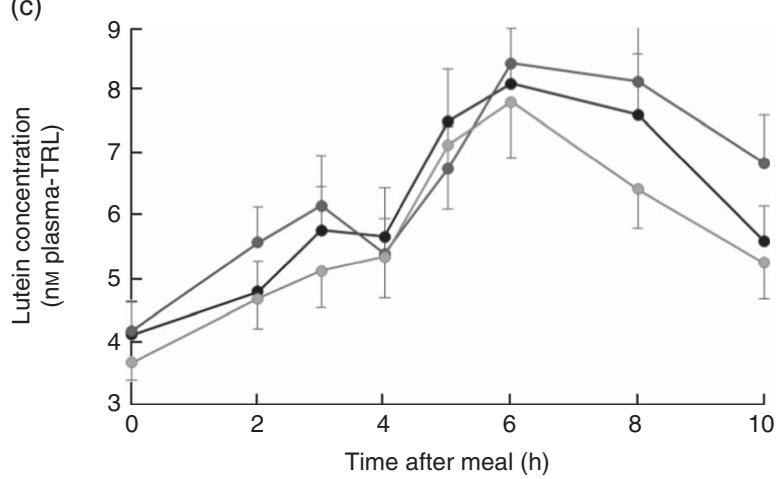

Including additional covariates such as BMI, body fat and fasting TAG and cholesterol concentrations into the statistical model did not change the absence of an effect of $\mathrm{Ca}$ on carotenoid absorption. Likewise, no effects were found when analysing data separately for the participants with $(n 6)$ and without elevated cholesterol levels ( $n$ 17)

\section{Discussion}

Previously, we investigated the effect of different doses of the macrominerals $\mathrm{Ca}$ and $\mathrm{Mg}$ and divalent trace elements ( $\mathrm{Fe}$ and $\mathrm{Zn}$ ), on the bioaccessibility of both pure carotenoid standards and carotenoids from different food matrices, including spinach, showing that $\mathrm{Ca}$ had a strong negative effect on the micellarisation of carotenoids ${ }^{(19,20,24)}$. As carotenoids are liposoluble, and as their intestinal uptake is ultimately related to the formation of lipid-bile-salt mixed-micelles, we hypothesised that supplemental dietary $\mathrm{Ca}$ would bind to fatty acids released from the lipids present in the test meal, and to the bile salts, hindering the formation of mixed-micelles and thus the delivery of carotenoids to the enterocytes, and also occluding carotenoids in the precipitates of fatty-acid soaps, which would eventually be excreted.

Although this hypothesis was previously observed in vitro, it remained to be confirmed in vivo, as it is possible that in a dynamic and biologically complex scenario of gastrointestinal digestion, the body might compensate for the precipitation-related

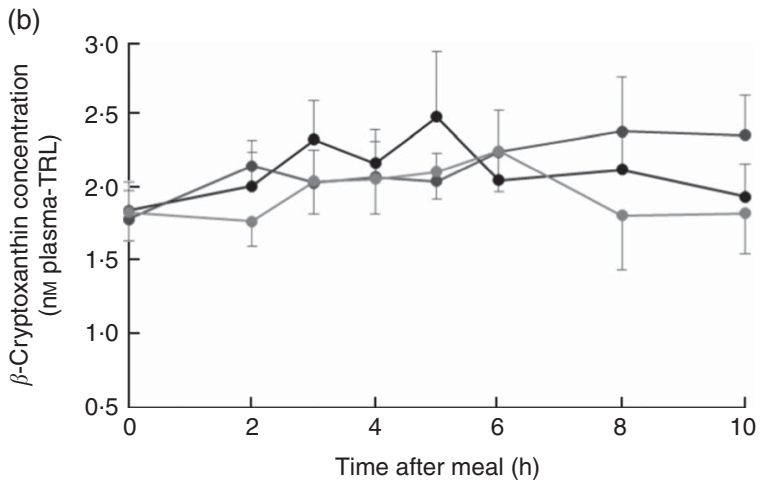

(d)

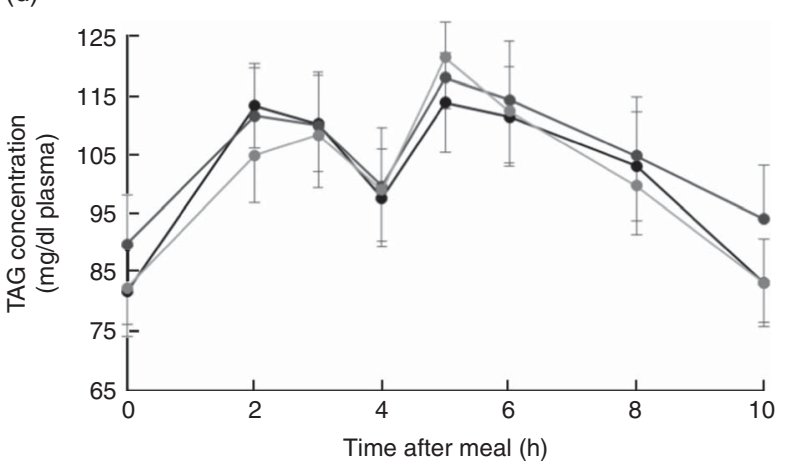

Fig. 3. Effect of different calcium doses on the postprandial plasma TAG-rich lipoprotein (TRL) concentration of carotenoids from a spinach-based meal. Changes in plasma TRL carotenoids of $\beta$-carotene (a), $\beta$-cryptoxanthin (b), lutein (c) and serum TAG (d) were assessed over a 10-h period after the intake of a test meal together with one of three doses of the calcium supplement (placebo, 500 or $1000 \mathrm{mg}$ of elemental calcium). Plasma TRL concentrations (nM) and plasma TAG concentrations $(\mathrm{mg} / \mathrm{dl})$ are expressed as mean values $(n 23)$ with their standard errors. - - Meal: placebo; - , meal: $500 \mathrm{mg} \mathrm{Ca;}-$ - meal: $1000 \mathrm{mg}$ Ca. AUC were compared for statistically significant differences as outlined in the 'Statistical Analyses' section. No statistically significant differences were found. 
Table 4. AUC results and maximum concentrations $\left(C_{\max }\right)$ for lutein, $\beta$-carotene and $\beta$-cryptoxanthin in the plasma TAG-rich lipoprotein (TRL) fractions, and for serum TAG, following the consumption of a spinach-rich test meal with either 0,500 or $1000 \mathrm{mg}$ supplemental calcium $(n 23)$

(Mean values with their standard errors; mean values and standard deviations)

\begin{tabular}{|c|c|c|c|c|c|c|}
\hline & \multicolumn{2}{|c|}{ Placebo group* } & \multicolumn{2}{|c|}{$500 \mathrm{mg} \mathrm{Ca}{ }^{2+}$} & \multicolumn{2}{|c|}{$1000 \mathrm{mg} \mathrm{Ca}^{2+}$} \\
\hline & Mean & SEM & Mean & SEM & Mean & SEM \\
\hline \multicolumn{7}{|l|}{ AUC } \\
\hline Lutein $(\mathrm{nmol} \times \mathrm{h} / \mathrm{l})$ & $22 \cdot 72$ & 5.44 & 24.29 & $5 \cdot 31$ & 21.38 & 5.41 \\
\hline$\beta$-Carotene $(\mathrm{nmol} \times \mathrm{h} / \mathrm{l})$ & 0.19 & 3.90 & 0.80 & $2 \cdot 77$ & -0.77 & 3.07 \\
\hline$\beta$-Cryptoxanthin $(\mathrm{nmol} \times \mathrm{h} / \mathrm{l})$ & $2 \cdot 80$ & 1.75 & 3.71 & 1.54 & $1 \cdot 20$ & 1.60 \\
\hline Total carotenoids $(\mathrm{nmol} \times \mathrm{h} / \mathrm{l}) \dagger$ & $25 \cdot 71$ & 9.58 & 28.81 & 7.72 & 21.81 & 8.40 \\
\hline TAG $(\mathrm{mg} \times \mathrm{h} / \mathrm{dl})$ & $210 \cdot 41$ & $50 \cdot 40$ & $163 \cdot 26$ & 54.98 & 193.81 & 36.92 \\
\hline \multicolumn{7}{|l|}{ Baseline TRL concentration $\ddagger$} \\
\hline Lutein $(\mathrm{nmol} \times \mathrm{h} / \mathrm{l})$ & 4.09 & 0.53 & $4 \cdot 20$ & 0.44 & 3.68 & 0.29 \\
\hline$\beta$-Carotene $(\mathrm{nmol} \times \mathrm{h} / \mathrm{l})$ & 3.78 & 0.56 & 3.55 & 0.54 & 3.76 & 0.56 \\
\hline$\beta$-Cryptoxanthin $(\mathrm{nmol} \times \mathrm{h} / \mathrm{l})$ & 1.85 & 0.20 & 1.79 & 0.19 & 1.84 & 0.22 \\
\hline Total carotenoids $(\mathrm{nmol} \times \mathrm{h} / \mathrm{l}) \dagger$ & $9 \cdot 72$ & 1.08 & 9.58 & 0.80 & $9 \cdot 37$ & 0.89 \\
\hline \multirow[t]{2}{*}{ TAG $(\mathrm{mg} \times \mathrm{h} / \mathrm{dl})$} & 81.47 & $7 \cdot 64$ & $90 \cdot 22$ & 8.24 & $82 \cdot 48$ & $6 \cdot 23$ \\
\hline \multirow{2}{*}{\multicolumn{7}{|c|}{$C_{\max \S}$}} \\
\hline & & & & & & \\
\hline Lutein (nmol/l) & 9.60 & 4.60 & $10 \cdot 34$ & $6 \cdot 36$ & 9.04 & 4.90 \\
\hline$\beta$-Carotene $(\mathrm{nmol} / \mathrm{l})$ & $5 \cdot 70$ & 3.57 & $5 \cdot 20$ & 3.05 & 5.79 & 3.46 \\
\hline$\beta$-Cryptoxanthin (nmol/l) & 3.28 & $2 \cdot 10$ & 3.15 & 1.76 & 2.94 & 1.59 \\
\hline TAG (mg/dl) & 131.61 & $40 \cdot 23$ & 133.91 & 46.64 & 133.43 & $40 \cdot 24$ \\
\hline
\end{tabular}

* Values were compared following generalised univariate linear models for each carotenoid and TAG, with AUC as the observed dependent variable, and carotenoid (lutein, $\beta$-carotene), participant, sequence of intervention (visits 1,2 or 3 ) and Ca supplemental dose $(0,5001000$ mg) as the independent, fixed factors. No significant effects were found. $\dagger$ Sum of lutein, $\beta$-carotene and $\beta$-cryptoxanthin.

$\ddagger$ Baseline (fasting) subtracted values - that is, concentration at time zero before test meal intake was subtracted from all following concentrations. $\S$ Reflecting highest concentrations measured, irrespective of the time point.

effects of Ca seen in vitro - for example, by up-regulating bile-salt and pancreatic enzyme secretion. By supplementing a spinach-based test meal with different high, but still physiologically plausible, supplemental doses of $\mathrm{Ca}$, we expected to note differences in the serum concentration of TAG and of carotenoids from the plasma TRL fraction (representing newly absorbed carotenoids) between meals supplemented with placebo (no additional $\mathrm{Ca}$ ) and those supplemented with either 500 or $1000 \mathrm{mg}$ of $\mathrm{Ca}$. However, statistical analysis of the carotenoid and TAG AUC of different meal groups showed no statistically significant differences between them. Interestingly, a very recent study investigating the effect of supplemental dietary $\mathrm{Ca}$ on the bioavailability of lycopene from tomato paste has reported a decrease of $83 \%$ in lycopene bioavailability after supplementation with $500 \mathrm{mg}$ of elemental $\mathrm{Ca}$ as carbonate ${ }^{(28)}$, based on postprandial plasma samples measured over $7 \mathrm{~h}$. Thus, despite not finding any significant effects of $\mathrm{Ca}$ on the bioavailability of spinach-borne carotenoids, our original hypothesis is not to be completely discarded.

Different factors could have played a role in the different outcomes of these two studies, including differences in test meal composition (spinach $v$. tomato paste, with respect to richness in insoluble fibre), the profile of the individual carotenoids in the test meal (being more apolar for lycopene) and the investigated target compartment (TRL $v$. plasma). For example, bioavailability of carotenoids has been shown to improve after processing of the food matrix. Plasma concentrations of lutein and $\beta$-carotene have been reported to be significantly higher from the intake of spinach leaves that were liquefied/puréed, compared with minced or whole-leaf spinach $^{(29,30)}$. Another study reports a higher bioavailability of total and all-trans-lycopene from tomato paste compared with fresh tomatoes ${ }^{(31)}$. In the present study, spinach meals given to participants were composed of whole leaves, which may have introduced issues of low bioaccessibility in the study design. In previous in vitro trials, where we compared bioaccessibility from different food matrices, total carotenoids from green leafy varieties (spinach and field salad) had markedly lower bioaccessibilities than those from liquid matrices (carrot or tomato juice $)^{(25)}$. Also, in vivo trials have shown that the bioavailability of carotenoids from spinach is inferior to that from other dietary sources $^{(32,33)}$, possibly related to their storage in pigmentprotein complexes, which renders carotenoids less accessible than those stored in chromoplasts (as it is the case for tomato) ${ }^{(34)}$. Considering the amount of individual carotenoids estimated to be present in the spinach test meal (Table 4), and their low bioaccessibility, and that the percentage of carotenoids effectively taken up by the intestinal lumen is lower than its actual bioaccessibility, the resulting low bioavailability may have impeded finding significant effects of the Ca supplementation, despite the relatively large number of participants and the crossover design. When comparing - for example, the AUC from the present study with that of other trials with various carotenoid-containing food sources - the observed values are relatively low ${ }^{(16,26)}$, though they are comparable with another recent trial with $\operatorname{spinach}^{(35)}$.

However, this does not explain the lack of a significant effect of Ca supplementation on the TAG AUC. Ca ions can bind both bile acids and NEFA to form bile salts and fatty-acid soaps of low solubility, respectively, which tend to complex and precipitate ${ }^{(36,37)}$. Previous trials carried out in animals ${ }^{(36)}$ and humans ${ }^{(38)}$ have reported an increase in faecal fat excretion 
when meals were supplemented with Ca. Furthermore, in a recent meta-analysis of randomised controlled trials testing the effects of dairy products and dietary supplements on faecal fat excretion, results indicated that increasing the intake of dietary Ca to $1241 \mathrm{mg} / \mathrm{d}$ impaired the absorption of dietary fat and increased faecal fat excretion ${ }^{(39)}$. In fact, according to the EFSA (European Food Safety Authority) Scientific Opinion on dietary reference values for $\mathrm{Ca}$, dairy products remain the main dietary sources of $\mathrm{Ca}$ in Europe, and the average intake in adults $(>18$ years) is between 690 and $1122 \mathrm{mg} / \mathrm{d}^{(40)}$.

In the present study, calcium carbonate supplements were provided in the form of gelatine capsules, and participants were asked to take them at the end of the meal with $300 \mathrm{ml}$ of water. By comparison, in the study by Borel et $a l^{(28)}$, calcium carbonate supplementation was provided in the form of effervescent pills dissolved in water, and taken together with the meal. Thus, the different form of the Ca supplement and the test meals (liquid $v$. solid and fibre rich) could have resulted in different mixing patterns during digestion. Also, pectins in the tomato paste could have formed a gel with the added $\mathrm{Ca}^{(41)}$. In addition, spinach contains oxalic acid $(0.97 \mathrm{~g} / 100 \mathrm{~g})^{(42)}$, which may have chelated $\mathrm{Ca}$ to some degree, though surely not entirely (molar ratio of $\mathrm{Ca}$ : oxalic acid approximately 1.6 for the meal highest in $\mathrm{Ca}$ ). Finally, it cannot be completely excluded that the different type of participants included in the present study, compared with those in the study by Borel et al., contributed to the different observations as follows: elderly participants included in the present study may tend to have lower plasma carotenoid levels; likewise, their BMI was somewhat higher; and participants had, in part, either elevated cholesterol or TAG; and these factors are known contributors to interindividual plasma carotenoid variability ${ }^{(43)}$

Finally, other aspects to consider are the physiological and genetic variability between participants. Although individual differences in enzymatic activity and concentration of bile acids during gastrointestinal digestion ${ }^{(44)}$ could influence the degree of bioaccessibility of carotenoids from one participant to the other, genetic variability could predispose participants to a higher or lower uptake efficiency of carotenoids in the enterocyte and downstream transport into the bloodstream via the chylomicrons ${ }^{(15,43)}$. On the other hand, as the intraindividual variability has been estimated to be approximately half of the interindividual variability, week-to-week variations within one participant could be substantial ${ }^{(43)}$. Analysis of the serum and plasma samples for fasting levels of TAG and carotenoids, respectively, on each clinical visit day, showed that values varied from week to week, without any specific trend and for inexplicable reasons, especially for the circulating carotenoids. Although participants were asked to avoid foods containing carotenoids before the first clinical visit, in order to lower the plasma carotenoid concentration, it should be noted that 2 weeks may not be sufficient to completely clear circulating carotenoids in blood plasma fractions, as the body stores dietary carotenoids in different organs and tissues: for example, the liver and adipose tissues ${ }^{(43)}$. However, at the time of the first clinical visit, the concentration of total circulating plasma carotenoids had dropped on average by $38 \%$, and longer washout periods would have been ethically questionable because of the difficulty in excluding coloured fruits and vegetables from the daily diet for a prolonged period of time.
Although this study had its strengths, including a doubleblinded, randomised, placebo-controlled trial design in which each participant was his or her own control, a high protocol adherence by the participants and a randomised block design where all six possible combinations of $\mathrm{Ca}$ intake were realised (high, medium-low $v$. medium-high-low, etc.), it also had its limitations. Only the effect of high doses (i.e. 50 or $100 \%$ of RDA) of Ca was tested for short-term treatments, and only spinach was chosen as a representative carotenoid leafy vegetable. Also, the intake of dietary Ca was not assessed, which may have potentially enhanced the variance of responses, as it was suggested that low-Ca consumers tend to utilise more transcellular absorption pathways, as opposed to participants with a higher intake, in whom paracellular pathways possibly play a role, and thus kinetics of Ca disappearance from the gut could differ ${ }^{(45)}$, which may have influenced carotenoid interactions. Faecal TAG excretion was not considered in the experimental design to reduce the burden on the participant.

In conclusion, despite the negative effects of divalent minerals on the in vitro bioaccessibility of carotenoids reported earlier, we did not find a statistically significant effect of Ca supplementation on the bioavailability of individual carotenoids from a spinachbased meal. Nevertheless, a recent human trial with another carotenoid source indicated that, under certain conditions, divalent minerals may in fact negatively affect carotenoid uptake. It can be speculated from these human trials that the effect of mineral supplements on the bioavailability of carotenoids, and potentially other liposoluble nutrients, may depend on the interaction of the supplement form with the type of carotenoid and the food matrix. Further investigations are necessary to fully understand the complex interactions taking place during gastrointestinal digestion between divalent minerals and carotenoids.

\section{Acknowledgements}

The support by the Luxembourg Fonds National de la Recherche (grant no. C11/SR/1268260) is highly appreciated.

Many thanks to Boris Untereiner and Aude Corvisy for technical support. The authors are grateful for the help of Dr Anna Chioti and the research nurses Jérôme Graas, Jean-Yves Ferrand, Alain Noirhomme and Thérèse Bagnah. The authors also thank Stephen Senn and Michel Vaillant for help and counselling with the statistical analysis and participant randomisation. The expertise of Dr Jacques Berlo and his team during the formulation of the $\mathrm{Ca}$ supplements and placebo pills is highly valued. The authors thank all participants who volunteered for this study for their cooperation. The study was conducted in the clinical facilities of the CIEC, headed by M. G., who aided in preparing the documents for the ethical committee and supervised the human clinical trial.

T. B. and L. H. planned and designed the study. J. C.-R. coordinated and carried out the major part of the human trial. C. G. organised the carotenoid analyses. K. B. and B. W. conducted the blood biochemistry and haematology analyses. E. R. supervised the PhD student (J. C.-R.) and aided in the planning and writing-up of the study. The manuscript was written by J. C.-R. and T. B., with additional input from all other authors. The authors declare that there are no conflicts of interest. 


\section{References}

1. Hamer M \& Chida Y (2007) Intake of fruit, vegetables, and antioxidants and risk of type 2 diabetes: systematic review and meta-analysis. J Hypertens 25, 2361-2369.

2. Osganian SK, Stampfer MJ, Rimm E, et al. (2003) Dietary carotenoids and risk of coronary artery disease in women. $\mathrm{Am}$ J Clin Nutr 77, 1390-1399.

3. Key TJ, Appleby PN, Travis RC, et al. (2015) Carotenoids, retinol, tocopherols, and prostate cancer risk: pooled analysis of 15 studies. Am J Clin Nutr 102, 1142-1157.

4. Li X \& Xu J (2014) Meta-analysis of the association between dietary lycopene intake and ovarian cancer risk in postmenopausal women. Sci Rep $\mathbf{4}, 4885$.

5. Buijsse B, Feskens EJ, Schlettwein-Gsell D, et al. (2005) Plasma carotene and alpha-tocopherol in relation to $10-\mathrm{y}$ all-cause and cause-specific mortality in European elderly: the Survey in Europe on Nutrition and the Elderly, a Concerted Action (SENECA). Am J Clin Nutr 82, 879-886.

6. Faber M \& Laubscher R (2008) Seasonal availability and dietary intake of beta-carotene-rich vegetables and fruit of 2-year-old to 5-year-old children in a rural South African setting growing these crops at household level. Int J Food Sci Nutr 59, 46-60.

7. Weber D \& Grune T (2012) The contribution of beta-carotene to vitamin A supply of humans. Mol Nutr Food Res 56, 251-258.

8. Liu R, Wang T, Zhang B, et al. (2015) Lutein and zeaxanthin supplementation and association with visual function in age-related macular degeneration. Inves Ophthalmol Vis Sci 56, 252-258.

9. Wang X, Jiang C, Zhang Y, et al. (2014) Role of lutein supplementation in the management of age-related macular degeneration: meta-analysis of randomized controlled trials. Ophthalmic Res 52, 198-205.

10. Krinsky NI \& Johnson EJ (2005) Carotenoid actions and their relation to health and disease. Mol Aspects Med 26, 459-516.

11. Kaulmann A \& Bohn T (2014) Carotenoids, inflammation, and oxidative stress - implications of cellular signaling pathways and relation to chronic disease prevention. Nutr Res $\mathbf{3 4}$, 907-929.

12. Bohn T, McDougall GJ, Alegria A, et al. (2015) Mind the gapdeficits in our knowledge of aspects impacting the bioavailability of phytochemicals and their metabolites - a position paper focusing on carotenoids and polyphenols. Mol Nutr Food Res 59, 1307-1323.

13. Borel P (2003) Factors affecting intestinal absorption of highly lipophilic food microconstituents (fat-soluble vitamins, carotenoids and phytosterols). Clin Chem Lab Med 41, 979-994.

14. Bohn T (2016) Bioactivity of carotenoids - chasms of knowledge. Int J Vitam Nutr Res 10, 1-5.

15. Borel P (2012) Genetic variations involved in interindividual variability in carotenoid status. Mol Nutr Food Res 56, 228-240.

16. Unlu NZ, Bohn T, Clinton SK, et al. (2005) Carotenoid absorption from salad and salsa by humans is enhanced by the addition of avocado or avocado oil. J Nutr 135, 431-436.

17. Bohn T (2008) Bioavailabilty of non-provitamin A carotenoids. Curr Nut Food Sci 4, 240-258.

18. Biehler E \& Bohn T (2010) Methods for assessing aspects of carotenoid bioavailability. Curr Nutr Food Sci 6, 44-69.

19. Corte-Real J, Iddir M, Soukoulis C, et al. (2016) Effect of divalent minerals on the bioaccessibility of pure carotenoids and on physical properties of gastro-intestinal fluids. Food Chem 197, 546-553.
20. Biehler E, Hoffmann L, Krause E, et al. (2011) Divalent minerals decrease micellarization and uptake of carotenoids and digestion products into Caco-2 cells. J Nutr 141, 1769-1776.

21. Institute of Medicine (2005) Dietary Reference Intakes for Calcium, Phosphorus, Magnesium, Vitamin D and Fluoride. Washington, DC: National Academies Press.

22. Souci SW, Fachmann W \& Kraut H (2000) Food Compoisition and Nutrition Tables, Vol. 6. Stuttgart: CRC press.

23. Biehler E, Kaulmann A, Hoffmann L, et al. (2011) Dietary and host-related factors influencing carotenoid bioaccessibility from spinach (Spinacia oleracea). Food Chem 125, 1328-1334.

24. Corte-Real J, Bertucci M, Soukoulis C, et al. (2017) Effect of divalent minerals on the bioaccessibility of carotenoids from food matrices and on physical properties of gastrointestinal fluids. Food Funct 8, 1008-1019.

25. Institute of Medicine (2001) Dietary Reference Intakes for Vitamin A, Vitamin K, Arsenic, Boron, Chromium, Copper, Iodine, Iron, Manganese, Molybdenum, Nickel, Silicon, Vanadium, and Zinc. Washington, DC: Institute of Medicine.

26. Bohn T, Blackwood M, Francis D, et al. (2013) Bioavailability of phytochemical constituents from a novel soy fortified lycopene rich tomato juice developed for targeted cancer prevention trials. Nutr Cancer 65, 919-929.

27. Unlu NZ, Bohn T, Francis D, et al. (2007) Carotenoid absorption in humans consuming tomato sauces obtained from tangerine or high-beta-carotene varieties of tomatoes. J Agric Food Chem 55, 1597-1603.

28. Borel P, Desmarchelier C, Dumont U, et al. (2016) Dietary calcium impairs tomato lycopene bioavailability in healthy humans. Br J Nutr 116, 2091-2096.

29. Castenmiller JJ, West CE, Linssen JP, et al. (1999) The food matrix of spinach is a limiting factor in determining the bioavailability of beta-carotene and to a lesser extent of lutein in humans. J Nutr 129, 349-355.

30. Rock CL, Lovalvo JL, Emenhiser C, et al. (1998) Bioavailability of beta-carotene is lower in raw than in processed carrots and spinach in women. J Nutr 128, 913-916.

31. Gartner C, Stahl W \& Sies H (1997) Lycopene is more bioavailable from tomato paste than from fresh tomatoes. $\mathrm{Am} \mathrm{J}$ Clin Nutr 66, 116-122.

32. Tang G, Qin J, Dolnikowski GG, et al. (2005) Spinach or carrots can supply significant amounts of vitamin A as assessed by feeding with intrinsically deuterated vegetables. $A m \mathrm{~J}$ Clin Nutr 82, 821-828.

33. Chung HY, Rasmussen HM \& Johnson EJ (2004) Lutein bioavailability is higher from lutein-enriched eggs than from supplements and spinach in men. J Nutr 134, 1887-1893.

34. Jeffery J, Holzenburg A \& King S (2012) Physical barriers to carotenoid bioaccessibility. Ultrastructure survey of chromoplast and cell wall morphology in nine carotenoid-containing fruits and vegetables. J Sci Food Agric 92, 2594-2602.

35. Eriksen JN (2016) Metabolism and potential health effects of carotenoids following digestion of green leafy vegetables - an interdisciplinary approach. $\mathrm{PhD}$ thesis, University of Copenhagen.

36. Gacs G \& Barltrop D (1977) Significance of Ca-soap formation for calcium absorption in the rat. Gut 18, 64-68.

37. Hofmann AF \& Mysels KJ (1992) Bile acid solubility and precipitation in vitro and in vivo: the role of conjugation, $\mathrm{pH}$, and $\mathrm{Ca} 2+$ ions. J Lipid Res 33, 617-626.

38. Chai W, Cooney RV, Franke AA, et al. (2013) Effects of calcium and vitamin D supplementation on blood pressure and serum lipids and carotenoids: a randomized, double-blind, placebo-controlled, clinical trial. Ann Epidemiol 23, 564-570.

39. Christensen R, Lorenzen JK, Svith CR, et al. (2009) Effect of calcium from dairy and dietary supplements on faecal fat 
excretion: a meta-analysis of randomized controlled trials. Obes Rev 10, 475-486.

40. European Food Safety Authority (2015) Scientific opinion on dietary reference values for calcium. EFSA J 13, 4101.

41. Soukoulis C \& Bohn T (2015) A comprehensive overview on the micro- and nano-technological encapsulation advances for enhancing the chemical stability and bioavailability of carotenoids. Crit Rev Food Sci Nutr (Epublication ahead of print version 11 June 2015).

42. Haytowitz DB \& Matthews RH (1984) Composition of Foods. Vegetables and Vegetable Products - Raw, Processed and
Prepared. Agriculture Handbook, no. 8-11. Washington, DC: Department of Agriculture.

43. Bohn T, Desmarchelier C, Dragsted LO, et al. (2017) Host-related factors explaining interindividual variability of carotenoid bioavailability and tissue concentrations in humans. Mol Nutr Food Res 61, 1600685.

44. Ulleberg EK, Comi I, Holm H, et al. (2011) Human gastrointestinal juices intended for use in in vitro digestion models. Food Dig 2, 52-61.

45. Bronner F (2003) Mechanisms of intestinal calcium absorption. I Cell Biochem 88, 387-393. 